\title{
K-pop as a Social Movement: Case Study of BTS and Their Fandom ARMY
}

\author{
Priscilla Kim ${ }^{1}$ and Dr. Ethan Hutt ${ }^{1 \#}$ \\ ${ }^{1}$ Archbishop Mitty High School, San Jose, CA, USA \\ \#Advisor
}

\section{$\underline{\text { ABSTRACT }}$}

This study investigates K-pop and K-pop fandom as an ongoing social movement. With popular South Korean group BTS as a case study, I examine how their fans join together and use collective action to create social change. My research answered three primary questions: (1) "How have K-pop fans been involved in societal causes prior to their recent surge in activism in 2020?," (2) "To what extent does K-pop represent a social movement?," and (3) "Do either K-pop music or the artists themselves contribute to fan participation in social advocacy, and if so, how?" I find that K-pop fans do constitute a social movement due to their use of extra-institutional tactics, based on John Fiske's (1992) concept of fandom as "subversive by design," Henry Jenkins' (1992) participatory fan culture framework, and Social Movement Theory (King, 2011). I also further Yoon's (2017) thesis that pop culture can give those who face a lack of resources and authority a means to challenge the status quo, emphasizing K-pop fans' innovative use of social media mobilization. By explaining how K-pop and its fans can be understood as a social movement, my research rethinks how we consider K-pop fandom and at the same time encourages K-pop fans to continue their activism work and to expand further. Through a literature review and my own observations framed by theories, I conclude that Kpop fans demonstrate potential to be a powerful force for social change.

\section{Introduction}

Amid social upheaval within the United States in 2020, with the Black Lives Matter protests following the murder of George Floyd, K-pop fans seem to have joined forces with various groups fighting for social justice, being hailed as allies and online vigilantes. When BTS, a seven-member boy band from South Korea, donated \$1 million to the Black Lives Matter (BLM) campaign, their staunch fanbase named "Adorable Representative M.C. for Youth," more commonly known as ARMY, quickly followed and matched the million-dollar donation in less than 24 hours under the hashtag \#MatchAMillion on Twitter. While this appears to be an incredible feat for a bunch of fans, these "stans" are quite accustomed to rapid record-breaking efforts in the digital realm, primarily via basic online social media channels that facilitate high-speed communication. A number of K-pop fans have embraced the overlap between fandom and politics, engaging in online political activism as a collective fandom. Matching their colossal defense of their common favorite idols, K-pop fans have proven capable of uniting in a highly organized, systematic way to amplify social movements and demand for change (Bhandari et al., 2020; Bruner, 2020; Coscarelli, 2020).

Given that K-pop fans (1) already actively participate and assemble using online tactics within K-pop spaces and (2) utilize their organizational abilities to engage in social activism in addition to fandom, it is worthwhile to examine the nuances, implications, and potential for future social movement mobilization the K-pop fandom may have. My research investigates how a strong collective identity and K-pop fans' efforts contribute to their ability to reach beyond the genre of "K-pop." My first research question was "How have K-pop fans been involved in societal causes prior to their recent surge in activism in 2020?" My second research question was "To what extent does K-pop represent a social movement?" To answer this, I studied existing literature on fandom-based political participation and social activism, zoomed in on K-pop fans, and looked into Social Movement Theory (SMT) as introduced by various 
scholars. Seeing that one particular group and their fandom-BTS and ARMY — stood out in voicing support for social issues, my third and final research question was "Do either K-pop music or the artists themselves contribute to fan participation in social advocacy? If so, how?"

I find that K-pop fans do constitute a social movement, as they meet the key criteria required to be considered a social movement as advanced by Brayden King's (2011) conceptualization of Social Movement Theory, John Fiske's (1992) definition of fandom, and Henry Jenkins' (1992) participatory fan culture framework (Pacis, 2012). By explaining how K-pop and its fans can be understood as a social movement, my research rethinks the way we consider K-pop fandom and at the same time encourages K-pop fans to continue their activist work and to expand further, becoming more involved in order to create a larger serious presence for themselves and their causes within the broader realm of the sociopolitical world. Along with a thorough literature review on K-pop-related papers and my own observations of BTS and ARMY applying SMT, I conclude that K-pop fans demonstrate potential to be a powerful force for positive social change.

\section{Review of Existing Literature}

\section{K-pop related Literature}

Studies on K-pop fan activism are not as extensive in the literature as other existing academic fan studies are, largely in part due to the new and still emerging activism of contemporary K-pop fans on a global scale. However, research regarding fan culture and the broader phenomenon of fandom in general can still be applied and adapted to K-pop. Concentrations of popular culture focused on television and film series fans particularly have a robust background and are therefore useful to accomplish my research goal (Fiske, 1992; Jenkins, 1992).

K-pop has frequently been described in academia as a means to empower fans and provide them with a sense of purpose. From strengthening fans' affective identities and enabling them to make sense of their lives, K-pop has inspired fans from all across the globe_-namely Canada, Hungary, Indonesia, Latin America, the Philippines, Romania, and the United States, which were the focal subjects of studies I explored (Yoon, 2017; Han, 2017; Kuo et al., 2020; Marinescu \& Balica, 2013; Jang \& Song, 2017; Pack, 2014; Vargas Meza \& Park, 2014).

First, a paper on transcultural fandom and digital mediation of K-pop in Latin America, by author Han (2017), found that fans' assertion of their unique subcultural identity as a K-pop follower led them to act as cultural envoys, bridging the cultural gap between the locals in their home country and the people of Korea. By translating between the two different cultures, fans facilitate cross-cultural understanding and play a key role in globalizing K-pop fandoms, spreading Hallyu via K-pop to their native regions. Latin American fans' "affective identification with virtues of K-pop idols... in overcoming social struggles, especially class conflicts, in achieving their stardom induces [them] to construct new subjectivity in which social mobility is imagined" (Han, 2017). Fans internalize and apply to their daily lives the virtues encapsulated in K-pop stars that are indispensable to achieving their dreams, including hard work, dedication, and resilience. The norm in the K-pop industry is that prospective idols must undergo intense predebut training, which lasts on average two to seven years, without guarantee of debut; even after debut, K-pop idols continue toiling in an industry where success can take years to come to fruition, and only if one is lucky. Fans recognize that reality, and this narrative of success founded upon hard work that often involves overcoming financial struggles paints a tangible picture of social mobility, and fans see these idols as inspirational role models. Furthermore, the "intangible social exchange values that K-pop brings... to their personal lives" keeps Latin American fans united as a tight-knit community (Han, 2017). As one fan explained, "What we respect about K-pop is that it has granted us an opportunity to realize our dreams through the medium of music, brought us the joy of sharing an interest with our friends, and [taught us] to organize and... work as a team" (Han, 2017).

Furthermore, a Manila-based study - part of a wider investigation of South Korean media export consumption in the Philippines-focused on De La Salle University students found Filipino fans primarily use the Internet to 
access songs, videos, images, and updates on K-pop artists. One respondent explained how online crowdsourcing allows fans, herself included, to feel closer to their favorites: "Fans are able to share their fan art, get info about their idols, and the idols themselves are able to communicate with their fans in a personal way" (Pack, 2014).

In light of the evident importance of online resources among K-pop fans, a quantitative analysis of K-pop in Spanish-speaking countries using data derived from Twitter found that the increasing preference of K-pop music resulted from the combined efforts of public broadcasting firms and fans. The main focus of the K-pop Twitter network structure was towards collective activities, notably K-pop fans watching K-pop TV programs or listening to music while tweeting, demonstrating their use of social media to engage in fandom in real-time (Vargas Meza \& Park 2014). The frequency of active tweeting and rapid communication among K-pop fans has important implications in regard to acting as agents of globalization of cultural products, a focus of Vargas Meza and Park's study (2014), and intraand cross-national activism through the use of active tweeting and other online methods.

\section{Literature on Social Media Activism}

Proponents of "social media use in activism have argued that the wide reach and fast pace of digital communications provide grassroots movements, charities, and humanitarian organizations with opportunities to galvanize support (Chadwick \& Howard, 2008; Housley et. al, 2018). Others suggest (Davies, 2013; White, 2010) that social media reduces activism to mere "clicktivism" or "slacktivism," where users "like" or forward content to show their approval for a cause but do nothing further.

Nevertheless, the hashtag can be a powerful asset: Thrift (2014) recounts how the \#YesAllWomen hashtag was used to share stories of female harassment and countered the defensive \#NotAllMen. The responsive capacity of the hashtag is also described by Horeck (2014), who highlights the repurposing of the commercial hashtag \#AskThicke into a feminist one.

The literature discussed in this review section clarifies (1) the dynamics of how K-pop fans interact in a digital, globalized, multicultural world, and (2) varying perspectives on the pros and cons of social media activism. Building off of this research as a foundation, I draw from a few select theories as well as my own modified definitions to critically evaluate the K-pop fandom and to detail how K-pop can be classified as a social movement, with BTS's ARMY being the main example.

\section{Methods}

During the earliest research stage, I began by reading news articles, media commentary, and public opinions on the topic at hand. Much K-pop news is spread via social networking services like Twitter, Instagram, Facebook, etc., and in order to gain the most up-to-date information regarding K-pop fan activism and insider perspectives, I observed mainstream public media on Twitter, where prolific online activity and communication of news updates occurs among K-pop fans. I analyzed national trends based in the U.S. on the Twitter Explore page to pinpoint relevant topics, checking daily from June 2020 to July 2020. When I started my research in June 2020, concurrent developments were unfolding, namely BLM protests and U.S. presidential election campaigns, which shaped the direction of my paper as I was inspired by current events for the direction of my paper. This contributed to the type of information collected, which relied more on contemporary sources and nascent empirical examples, as opposed to long historical processes. Recency is apt considering the very nature of pop culture and fandom is dynamic, and popular trends are constantly reorienting and adapting. To gain background knowledge on the commercial dynamics of K-pop as a musical industry and to explore literature surrounding social movements, the main academic databases I accessed were Google Scholar, JSTOR, ProQuest - Research Library Prep, SIRS Issues Researcher, ResearchGate, SpringerLink, and SAGE Journals. Key search terms include the following: "K-pop fandom," "K-pop influence and impact," "fan activism," "K-pop activism," "social movement theory," and "K-pop fans and politics." Coming across the work of media scholar Henry 
Jenkins (1992) in labelling participatory fan culture, I borrow Jenkins' framework and draw from several authors to inform my analysis and create a comprehensive definition of fandom, described as 'subversive by design' by Fiske (1992) and Yoon (2017) and significantly political as noted by Bennett (2014) and Fiske (1992) (Pacis, 2012). To define social movement, I draw from King's (2011) study on the tactical disruptiveness of social movements in corporate boycotts that identifies a unique extra-institutional nature; I then applied this framing to K-pop fan activism. While the literature I reviewed in regards to the historical context of K-pop was broad, I decided to focus my analysis primarily on BTS and their ARMY fandom and within the past decade, considering (1) BTS's preeminent social activism both empirically throughout their entire music career since 2013 and more recently in 2020, (2) the extensive availability of primary and secondary sources in the media and literature, and (3) BTS's peak popularity in the U.S. from 2017 to 2021 which prompted many Western media outlets to write about ARMY, especially following pivotal political events in 2020 and the surge in fan activism that ensued.

\section{Background of K-pop and Introduction to K-pop Fandom}

In this section, I will clarify what K-pop and K-pop fandom is. First, K-pop is a style of South Korean popular music characterized by catchy assorted melodies, intricate choreographed dances, flashy music videos, stylized group images, and most importantly, the artists, commonly referred to as "idols" (Romano, 2018). These factors distinguish this genre from other well-liked forms of Korean music such as trot, sentimental ballads, or K-hiphop. Following the tide of growing global popularity of South Korean culture called Hallyu (also Hanryu), or the "Korean Wave," that began in the 1980s, K-pop first burgeoned in the 1990s and became popularized in the 2000s to the early 2010s. It then spiked in the late 2010s-especially when BTS won Top Social Artist at the 2017 Billboard Music Awards (BBMAs), the first K-pop group to do so-and has been soaring in popularity ever since (Blake, 2018).

Now I will introduce the K-pop fandom. At the turn of the twenty-first century, widespread internet communication was not as prevalent as it is in the post-industrial, technology-driven society in 2021; therefore, the earliest K-pop fans were confined to communication via niche online web forums or local in-person gatherings. Nonetheless, since its inception, K-pop fans have showcased a noteworthy ability to organize large-scale collective efforts, such as fan-led birthday projects and stacks of decorated rice bags donated to charity in the name of their idols known as 'fan rice' (Mahr, 2012). Analogous fan-organized activities have progressed into the latter 2010s and early 2020s, including buying giant K-pop billboards, running socially conscious donation drives, and systematic group streaming on music services like Youtube and Melon to raise song rankings that factor in for recognition at year-end awards ceremonies or wins on music shows where K-pop artists promote their new music (Herman, 2017; Jeong, 2017; Jeong, 2020; Yang, 2019).

\section{Defining Fandom through a Political Lens}

To support my line of reasoning of whether K-pop is a social movement, I use John Fiske's description of fandom as 'subversive by design' and a 'largely political activity,' qualities that refer to fans coalescing in a way that can have great political influence due to a shared, accumulative zeal for their particular object of fandom-in this case, K-pop. The mass mobilization of fans, who constitute a significant portion of the general public, follows (Fiske, 1992; Pacis, 2012). 'Subversive by design' alludes to the fact that fans give great influence to their favorite stars, and the function of fandom in mass action has the revolutionary capacity to undermine existing social structures. Adding onto this definition, I argue that K-pop as a subculture is utilized to challenge traditionally powerful figures, from mainstream media to government authority, to disturb the social order in a positive fashion. My thesis is similar to the conclusion of Yoon's (2017) study on transnational Canadian K-pop fans' experiences of cultural hybridity, which concludes, “fans' global imagination can be analyzed as a subversive or regressive cultural practice... Popular cultural texts can 
give young people who struggle with a lack of resources and authority a cultural means through which dominant social orders are negotiated."

\section{Participatory Fan Culture}

Jessamine Joyce C. Pacis' undergraduate thesis titled Popping the K-pop Bubble: A Study on the World of K-pop Fandom as a Subculture heavily guided the direction of this paper and the thinking that went into it. Inspired by Pacis' in-depth review, I incorporate media scholar Henry Jenkins' synopsis of participatory fan culture as a way to frame answers to my research questions and to study the K-pop fan community. Jenkins' framework describes how participatory culture, as opposed to consumer culture, consists of members of a fandom who not only consume media content but also create and distribute it as contributors or "prosumers." In "In My Weekend-Only World...: Reconsidering Fandom" at the end of Textual Poachers, Jenkins (1992) concludes that the "complexity and diversity of fandom" involves five levels of activity:

1. a particular mode of reception,

2. a particular set of critical and interpretive practices,

3. a base for consumer activism,

4. particular forms of cultural production, aesthetic tradition, and practices, and

5. functions as an alternative social community (p. 277-281).

These make up the key elements of participatory fan culture, and I use this framework to examine and define the K-pop fandom as an ongoing social movement, adapting the five categories as necessary to make sense of fan practices in the modern digitized world. Lucy Bennett's (2014) evaluation through the lens of Jenkins' Textual Poachers of how technological advances have impacted fandom, distinctively in the area of organizational and civic power, is thus meaningful. My paper continues the seminal Textual Poachers' groundbreaking narrative of rejecting the view of the fan as a passive, irrational consumer and places a new emphasis on present-day K-pop fans (Jenkins, 1992).

\section{What is a Social Movement?}

Using Social Movement Theory, I define a social movement as "a group of united individuals acting collectively and using extra-institutional methods to bring about social or political change." This takes from Brayden King's study on the tactical disruptiveness of social movements in corporate boycotts. According to King (2011), social movements are a distinct form of collective action due to their use of extra-institutional tactics to accomplish their goals, and groups must organize aggrieved individuals and generate collective action in pursuit of a collective good.

An application of each of the five parts of Henry Jenkins' participatory fan culture framework along with a definition of fandom that draws from the work of John Fiske, Kyong Yoon, and Lucy Bennett helps clarify the specific criteria that make K-pop fans a social movement. I find that K-pop does indeed qualify as a social movement, considering the subversive K-pop "stan culture" activity, their undoubtedly participatory nature, and their usage of extrainstitutional methods to attain collective objectives, importantly social justice (King 2011; King \& Soule, 2007).

\section{Results}

In this Results section, I will apply fandom-related and social movement theories to K-pop. In the first subsection, I will apply Jenkins' (1992) Participatory Fan Culture framework to K-pop. In the second subsection, I will dive into the history of K-pop fans acting for social causes and past examples of collective action in order to answer my first 
research question, which was "How have K-pop fans been involved in social causes before 2020?" In the third subsection, I will explore K-pop political activism in 2020, answering my second research question: "To what extent does K-pop constitute a social movement?"

\section{Applying Participatory Fan Culture to K-pop}

To analyze the nature of K-pop as a social movement, I will prove how the characteristics in Henry Jenkins' participatory fan culture framework are suitable to the K-pop world.

Jenkins' (1992) first point in the participatory fan culture framework is a "particular mode of reception." The findings observed in the prior literature review section (Pack, 2014; Vargas Meza \& Park, 2014) support that K-pop fans do have a particular way of reception, one that is primarily facilitated by the internet and social media. Studies on diasporic (second-generation or later immigrant) youth, international fans, and LGBTQ+ Asian Americans that offer K-pop is a safe space for them to reconstruct their identities and find representation in also sustain that K-pop fandom is an "alternative social community," Jenkins' fifth point (Han, 2017; Kuo et al., 2020; Marinescu \& Balica, 2013; Vargas Meza \& Park, 2014).

K-pop fandoms also carry a "particular set of critical and interpretive practices" and "forms of cultural production, aesthetic tradition, and practices," which are Jenkins' (1992) second and fourth points, respectively. K-pop fans are highly active in terms of producing their own cultural texts, being part of one of the most robust participative fan cultures. The K-pop community shares many practices common to most pop culture fandoms but also contains unique differences, including fan videos (specifically 'fancams,' or K-pop stage performances focusing on one individual group member recorded by fans in the audience), fan edits, fan-translated videos of the original media but with subtitles added in their native language (e.g., English subtitles), and K-pop song lyric videos. Also common are fan art, fanchants, fanfiction with original 'AUs' or alternative universes, K-pop dance covers, K-pop instrumental and singing covers-often covered in self-translated English versions—-fan translational practices from Korean to the various languages of international fans, and K-pop album photocard trading, selling, and making (Aisyah et al., 2019). All this evidences that K-pop fandom does indeed function as an alternative community with its own distinct culture and productivity (Jenkins, 1992). Jenkins' third point, "a base for consumer activism," elicits a more in-depth exploration that I will discuss in the section hereafter.

More intriguing and unique to the K-pop fandom are the inherent structural barriers to access K-pop primarily faced by international fans, i.e., not being fluent in the primary language (Korean) or being unable to attend events held in Korea because they live in another country. Interestingly, most of the fans involved in the significant political events of 2020 consist of international backgrounds, especially American fans. Overseas K-pop fans' devotion for their favorite groups transcends limits and arguably adds to their longing to reconcile that additional distance. Ideas of cross-cultural similarity (Chin \& Morimoto, 2013), and cultural shareability (Singhal \& Svenkerud, 1994) disprove the idea that alienation arises from linguistic, cultural, and geographical boundaries. Despite societal barriers, similarities connect fans across cultures in ways that overcome mass media culture, and audiences from different backgrounds often share common universal values that enable music to flow across cultural boundaries (Yoon, 2017; Han, 2017). Such unique nuances and dimensions among the K-pop fandom contribute to their robust collective identity that helps them achieve specific goals that extend to political efforts and solidify Fiske's understanding of fandom as largely political and subversive by design, because it blurs national and cultural lines.

\section{History of K-pop Fans for Social Causes and Mass Collective Action}

Recall the 'Background of K-pop and Introduction to K-pop Fandom' section, which briefly described the ways in which celebratory K-pop culture operates and how fans show their avid loyalty (e.g., sending idols high-end luxury items as gifts and fan rice). Beginning around the late 2000s and continuing a decade later, the fan rice tradition involves fans raising money to donate bags of rice to people who cannot afford food and other basic commodities, in 
the name of their favorite idols. The scope of these fans' donations is perhaps best demonstrated by when 50 fan clubs from all around the world donated a hefty 12.7 tons of rice at a Big Bang concert in 2012 (Mahr, 2012)—Big Bang is a second-generation (2003-2010) K-pop group often said to have pioneered the international K-pop scene.

Many K-pop fans also donate to various social, environmental, and wildlife-protecting causes for their favorite artists' birthdays, accrediting these acts of benevolence to their favorites (Zheng, 2018). Fans have increasingly fundraised for ad hoc issues as well, calling for monetary support for events like natural disasters and humanitarian emergencies as they arise via social media (Gogoi, 2020; Roberts, 2020). These actions demonstrate that K-pop fandom is socially aware and that they contribute tangible support to reduce injustices and suffering in the world, many of which affect fans' direct communities.

Gifts are not limited to charitable donations either: fans will regularly pitch in to purchase billboard space to publicly air ads promoting their favorite artists, i.e., in Times Square or local subway stations (Jeong, 2020; Herman, 2017). Not to mention, fans - particularly ARMY - ordinarily sell out concerts with massive venues in a matter of minutes, petition local radio stations to play K-pop songs, and boycott exclusionary music awards shows (Bruner 2020; Reuters 2020; Coscarelli 2020). This type of resistance is reflected when K-pop fans openly voiced their resentment after their comments to include K-pop were ignored by the popular Peruvian dance reality show El Gran Show, which forced El Gran Show to listen to their opinions due to their significant viewer presence and refusal to be disregarded. This instance of activism illustrates that K-pop fandom is not restricted to affective consumption only, but also creates affective labor to challenge power and resist dominant structures, in this case mainstream Peruvian media and also Western culture globally (Han, 17).

The casual routine with which K-pop fans wield such monetary power is almost shocking, and proves they are a base for consumer activism and collective action. As one BTS fan explained, "We' re buying cars and selling out stadiums; you can't just do that with some overexcited girls. This is... an economic force, and something you can't really dismiss as... trivial" (Bhandari et al. 2020). Furthermore, K-pop fans singularly express joint organizational power when they systematically "stream" on online music services to break records and increase the standing of their favorites (Jeong 2017; Yang 2019).

K-pop fans have long demonstrated power for goal-oriented coordination and vast mobilization. An exploratory study of Hallyu (Korean Wave) fanclubs in the Philippines found three main purposes for the formation of fanclubs - the majority of which were initiated by fans themselves, as opposed to the official fanclubs established by Korean entertainment agencies who manage the Hallyu stars-are (1) to support the K-pop artist, (2) to unify Filipino fans, and (3) to market the artist (Deen, 2014). The most common fanclub activities involved actions to unify fans and endorse the artist, including mass voting, flash mobs, hosting a radio station, and communal fan gifts and packages (Deen, 2014). Whether it be securing a music show "win”_-an important measure of a K-pop group's success—or ensuring their favorite artist trends frequently, collectively these fans have a huge online presence, manifested by the fact that K-pop was the most tweeted about music genre worldwide in 2019, with over 6.1 billion related tweets, a 15\% increase from 2018 (Coscarelli 2020). The most tweeted about artist for the last three years was BTS, and only two days in May of 2020 did a BTS-related term not trend globally on Twitter (Coscarelli 2020). K-pop artists also consistently outperform in the number of expected Twitter mentions relative to their overall follower size; EXO, a nine-member K-pop boy band, and BTS most strikingly exhibit an engagement rate of, respectively, about 14,000 and 4,000 times more than expected by metrics from Next Big Sound, a music data analytics company run by Pandora (Blake, 2018).

My first research question was "How have K-pop fans been involved in societal causes prior to their recent surge in activism in 2020?" Clearly, K-pop fans have a history of being vastly involved in all aspects of fandom, from economic to social to musical questions. As immersed as these fans are in the K-pop world, they are involved in sociopolitical issues that affect their daily lives outside of fandom, too. Many fans have leveraged the intersection between their fandom and politics, as we will explore in the next section to answer my second research question. 


\section{Politics and K-pop Activism in 2020}

Remarkably active fan behavior and mass productivity in the K-pop fandom translates easily to civic activism, given that the passion driving fans to dedicate their valuable time and money to K-pop idols can likewise be wielded to more promote social causes. In the summer of 2020, these ardent fans have proven able to come together and utilize their unique social media proficiency to demand for change and amplify social movements. This parallels their historic activism in defending what they love, but also goes beyond charity in new and unprecedented ways.

During the summer of 2020, K-pop fans gained widespread media attention for their active antiracist work in support of the Black Lives Matter movement in the United States. With racial injustices and police brutality pervading the streets of America, especially after the George Floyd case received attention not only from Americans but from citizens worldwide, many K-pop fans joined the fight against racism through their own singular methods of social activism. After BTS donated \$1 million to the BLM campaign, their fanbase ARMY matched the million-dollar donation using the Twitter hashtag \#MatchAMillion in under 24 hours, substantiating Housley and coauthors' (2018) argument that users' ability "to post and propagate content on social media in real time" ensures that incidents can be publicized quickly and related campaign messages can reach wide audiences while still topical. ARMY and several other K-pop fandoms further participated in BLM activism by flooding their K-pop fancams to overturn racist trending phrases and Twitter hashtags like "white lives matter"- - a counter to BLM - in effect diluting any actual offensive content (Bhandari et al., 2020). This repurposing of hashtags parallels Thrift (2014) and Horeck's (2014) descriptions of similar activity in online feminist movements. Moreover, masses of K-pop fans deployed their fancams on an app to report "illegal activity protests" run by the Dallas Police Department; fans sent in K-pop videos and memes to prevent police from tracking BLM protestors' actions through the app and caused it to be temporarily taken down (Reddy, 2020; Romano, 2020).

Although unconventional, these examples of collective fan mobilization in concert via extra-institutional methods align with my definition of a social movement and Brayden King's notes on Social Movement Theory. Kpop fans' methods count as extrainstitutional because they do not use governmental or policy methods to express their grievances, but rather equip unorthodox tactics like flooding fancams and mass collective action for donations, which support more grassroots efforts, thus qualifying as a social movement. Furthering this connection to movements and drawing from Yoon's (2017) thesis, this unique form of group mobilization among K-pop fans and Black, Indigenous, and People of Color (BIPOC) members of the K-pop community is arguably due to a lack of access to traditional means of political protest. Harnessing collective power via social media and other digital channels is highly accessible for groups like youth and minorities, who often lack said access to or a voice in political decisions, and especially for those who may not have the financial capacity to donate large sums or do not have their own source of earned income. In fact, following George Floyd's murder, efforts to raise BLM donations by watching a Youtube video celebrating Black poets and artists paralleled how K-pop fans systematically stream Youtube videos to raise views-both shared tactics to achieve a collective social goal (Toussaint, 2020). Thus, in light of these extra-institutional methods of political activism, the answer to my second research question, "To what extent does K-pop represent a social movement?" is that K-pop fandoms do constitute a social movement.

K-pop culture, indefinitely facilitated by digital technologies_echoing Lucy Bennett's (2014) ideas-serves as a means for fans to participate in political processes and to challenge the dominant social order through disruptive counteraction on social media. Blog author of "Ask a Korean!” who goes by pen name T.K. Park elucidates, "K-pop fans learned how to organize through their fandom. K-pop is a digital-native music," and South Korea's early implementation of nationwide broadband service "made Korean pop music respond to the demands of the internet, and also made K-pop's fandom the most sophisticated actors in the digital sphere" (Coscarelli, 2020).

Unlike other musical acts that have raised awareness for social causes, such as the political hip-hop movement in the 1980s, "K-pop's message is not necessarily political in an overt sense, [but] they are often about empowerment and self-confidence," T. K. Park says (Coscarelli, 2020). This brings up the question of whether K-pop music or the artists contribute to fan involvement in social advocacy, which was my third and final research inquiry. While 
various K-pop acts have expressed socially conscious and charitable deeds, one group and their fandom in particular stands out in their steady commitment and open stance against social injustices: BTS and ARMY.

\section{The ABC's of BTS}

In this section, I will summarize the history of BTS and what makes their music and philosophy unique. I will then go over their involvement in the UNICEF \#EndViolence campaign and their "Love Yourself" message and discuss instances of activism by their fandom ARMY. In doing so, I will answer my third research question, which was "Do either K-pop music or the artists themselves contribute to fan participation in social advocacy? If so, how?" By focusing on BTS as a case study, I find that the answer to this question is yes, due to the messages and activity of BTS and their fandom ARMY.

BTS's music takes influence from various genres, including hip-hop, pop, and R\&B, but their discography is more than just music. Rising out of humble beginnings since their debut in 2013, BTS, or Bangtan Boys, have become renowned globally for their meticulous choreography, elaborate music videos that connect to form a storyline, and high-quality songs with heartfelt lyrics that cover themes such as coming of age, mental health, self-love, and societal pressures. This artistry combined with a focus on creating meaningful music, in line with their record label's mission of "Music \& Artist for Healing," and the members' journey to success marked by immense personal hardship and equal hard work, represents the rags to riches archetype that inspires millions (Big Hit Entertainment, 2020).

Despite starting as the "underdogs of the underdogs" according to researcher Lee Jee-Heng (Yang, 2019), with inner resilience, sheer talent, and their authentic, entertaining personalities, more and more people began to take notice of them and turned into fans, leading to their massive global popularity in 2021. This quintessential success story serves as a source of hope to many, mainly their fans called ARMY. When fans feel low, they are encouraged by BTS's own efforts and the constant outpouring of love. Since their fledgling days as a group, BTS has taken great measures to actively engage with and convey their appreciation for their fans, social media playing a major role, and this has resulted in a sense of belonging among many ARMY. There is a reason why BTS won Top Social Artist at the BBMAs for four consecutive years from 2017 to 2020, with more than 300 million fan votes worldwide in 2017 (Blake, 2018). Although the bond between the BTS members and their millions of fans around the world is a parasocial, one-sided one in which the fan extends emotional energy and time, and BTS - the media persona-is unaware of the individual fan's existence, the fans develop a sense of intimacy and perceived friendship nonetheless (Horton \& Wohl, 1956).

Furthermore, BTS's involvement in the UNICEF \#ENDViolence campaign alongside their Love Myself Campaign cements their stance as global leaders for social good (Evangelista, 2019). BTS also attended the UN General Assembly in 2018 for the launch of Generation Unlimited, where BTS's leader Kim Namjoon (RM) gave a speech advocating self-empowerment: "I want to hear your voice, and I want to hear your conviction. No matter who you are, where you're from, your skin colour, gender identity: speak yourself. Find your name, find your voice by speaking yourself" (Lufadeju, 2018). These powerful words summarize the ethos of BTS and their music, which in turn encourages their fans ARMY to also strive to empower themselves and others.

Not only are BTS leaders in supporting humanitarian causes themselves, but ARMY have proven too to be one of the most pronounced and most numerous social advocates in the K-pop realm, as expressed via prior examples, and philanthropic fan work like One In An ARMY, the fan group that organised the \#MatchAMillion fundraising effort, and who has helped fund roughly 600 charity projects globally (Roberts, 2020). One In An ARMY is notable because they do not solely send money to already large, existent organizations, but instead fund their own start-up efforts and original local projects to assist their immediate communities that have a more direct and visible impact, in agreement with the extra-institutionality criteria of SMT. BTS and ARMY's parallel commitment to social justice demonstrates how a fandom's activism can mirror the example of the K-pop group.

As part of the upturn in antiracist activism during late May and June of 2020, many ARMYs have demonstrated vocal support and allyship for Black Lives Matter, coming together in antiracist mobilization to fight for racial 
justice and amplify the Black community; the $\$ 1$ million BLM donation being one of the most notable examples. It is also important to realize that ARMY is made up of a range of fans from diverse backgrounds, and many ARMYs are Black themselves, so race issues are something that affect their lives every day, beyond being a fan within the K-pop sphere. Likewise, Black ARMYs and K-pop fans had a crucial part in starting these conversations-commentary they have voiced for a long while now, far before the recent national and global focus on institutional racism in 2020_-and spurring BLM mobilization in the K-pop realm.

Although I focused on BTS and ARMY as the primary case study, it is worth noting that other K-pop groups and their respective fandoms have supported social causes with similar online mobilization, but on a less frequent, massive, and united scale. For example, fans of popular K-pop girl group Blackpink purposefully held back their social media capacity by not overtaking the list of trending hashtags on Twitter so as to allow Black Lives Matter content to trend and for the BLM activists' work to be seen. These considerate actions with the intention of not taking up space are commendable, and many other K-pop artists have denounced racism and individually donated to BLM organizations as well.

Lastly, it is necessary to acknowledge the negative sides of ARMY and K-pop fandom, who, despite their outstanding activism, are ill-reputed for frequently mistreating and alienating BIPOC fans in the K-pop community. $\mathrm{K}$-pop fans in the past have not always been a wholly positive proponent of good, and are still at many times exclusive. Furthermore, the complexity of the way that fans interact with one another and within K-pop fandoms is multi-layered, and there is not one overarching narrative that can be generalized to every single individual K-pop fan. This demonstrates all the more why K-pop fans should change the narrative and the skeptical perception surrounding them by continuing to do acts of good and standing up against injustice, hearing the voices of those in their fandom who often go unheard. No fandom is perfect, and this positive change in direction represents a call to action for K-pop fans to do better and to use their potential to be a powerful force for good.

\section{Discussion}

Based on these findings, we have reframed our understanding of K-pop and K-pop fandom, taking a closer look at BTS and their fanbase ARMY. Upon a literature review and application of Henry Jenkins' participatory fan culture framework and Social Movement Theory to several examples, I find that the efforts of K-pop fans have been consistent, intentional, and powerfully united. That K-pop fandom has been proven to fulfill the criteria for a social movement implies they are a significant social force that has worked, currently works, and would ideally continue to work as a social movement, growing in their already potent ability to collectively mass mobilize and take action on a global scale.

My findings suggest for both K-pop fans themselves and society at large to recognize K-pop fans, and fans as a broader group, as a powerful force with the potential to effect change. While it is ultimately up to the fans whether or not they use their collective organizing power for good, when they have chosen to do so in the past, positive impacts have indeed been felt. I hope that my results strongly substantiate and document that K-pop fans are not a "joke" or filled with "teenage pranksters or delinquents," but instead, a range of diverse individuals from various backgrounds who are passionate about contributing to change they want to see in the world. They are serious about these issues, because while they are fans, they are also humans and citizens who have lives made up of other parts of their identity outside of being a fan, and they care about many social issues as fundamentally human.

\section{Conclusion and Implications}

In this paper, I applied Social Movement Theory as defined by Brayden King (2011) to K-pop and K-pop fandomswith a focus on the "unprecedented socio-cultural success" of BTS and ARMY (Rojas, 2020). I concluded that (1) Kpop fans have been historically active in social causes before 2020, (2) K-pop fandom constitutes a social movement, 
and (3) K-pop music and artists do contribute to fan participation in social advocacy, as demonstrated by the case study of BTS.

Through Henry Jenkins' (1992) participatory fan culture framework, I identified unique fan practices, surrounding political dynamics, and means of participation that K-pop fans utilize to create mass collective action, embodying the notion of strength in numbers. Specifically, their use of non-traditional, extra-institutional methods of pursuing social change fits King's definition of Social Movement Theory. I also further Yoon's (2017) thesis that pop culture texts can give young people who face a lack of resources and authority a means to challenge the status quo, emphasizing the innovative use of social media mobilizing for sociopolitical change that is also used similarly in apolitical K-pop contexts.

Through actions such as using their joint collective power and digital proficiency for social good, K-pop fans are changing the narrative of fandom and changing how the media and academia views them. A movement in this direction would potentially bring about positive change.

\section{Future Research}

There are several possible avenues of future research. Currently, a large lack of data about K-pop fans and fan populations exists. Therefore, gathering more data and statistical evidence regarding sweeping fan demographics to gain a better sense of where various fans are from and where they are most concentrated across countries would be key. One such example is a fan-driven, collaborative research project called the ARMY Census 2020 circulating online in efforts to collect quantifiable data on global ARMY sociodemographics, which will likely open the doors to much research in the field (Rojas, 2020). However, this project is limited to just one fandom, ARMY. It would be eye-opening to measure the relative population distributions of fans of other K-pop groups and compare fandoms. Furthermore, it would be interesting to see how K-pop has influenced those fans' respective politics as an area of study. For example, in Thailand, fans used K-pop lyrics and memes by trending \#Dispatch to express frustration towards their government's handling of COVID-19, and Thai youth used K-pop dance and social media to mobilize and spread information at pro-democracy demonstrations (Tanakasempipat, 2020; Yim, 2020). Similarly, in 2019, Chile's government blamed K-pop and other "international media" for domestic anti-government protests (Reddy, 2020). Finally, studies using the norms of behavioral psychology, behavioral economics, or social psychology to examine fan motives and behavior would be interesting investigations from other disciplines.

\section{Limitations}

For my methods in producing this argumentative paper, I did not use highly technical forms of data collection or analysis. A more systematic, uniform approach would have strengthened the reproducibility of my research. Furthermore, the paper lacks any statistical analysis of trends in national Twitter feeds and news topics. However, the structure and set of definitions used to clarify my claims followed a logical procedure, and the application of social movement theory is applicable to other research fields that study organizational behavior.

\section{Acknowledgements}

I would like to thank Dr. Ethan Hutt for his feedback and for guiding me through the research and writing process. 


\section{References}

Aisyah, A., Zainudin, I. S., \& Yoan, R. S. (2019). Social Media Translational Action: Translation Activities by K-Pop Fans in Twitter. International Journal of Virtual and Personal Learning Environments (IJVPLE), 9(2), 32-54.

http://doi.org/10.4018/IJVPLE.2019070103

Bennett, L. (2014). Tracing Textual Poachers: Reflections on the development of fan studies and digital fandom, Journal of Fandom Studies 2(1), 5-20. https://doi.org/10.1386/jfs.2.1.5 1

Bhandari, A., Doyle, G., Coates, S. (2020, July 15). The mobilising power of the BTS ARMY. Reuters. https://www.reuters.com/article/us-global-race-bts-fans/the-mobilising-power-of-the-bts-army-idUSKCN24G0Q0

Bhandari, A. (2020, July 14). How BTS ARMY raised \$1 million for Black Lives Matter. Reuters Graphics. https:/graphics.reuters.com/GLOBAL-RACE/BTS-FANS/nmopajgmxva/

Blake, E. (2018, April 4). The Strength of K-Pop Fandom, By The Numbers. Forbes. https://www.forbes.com/sites/emilyblake1/2018/04/04/k-pop-numbers/\#4455308d48ab

Bruner, R. (2020, July 25). How K-Pop Fans Actually Work as a Force for Political Activism in 2020. Time. https://ime.com/5866955/k-pop-political/

Chin, B., \& Morimoto, L. H. (2013). Towards a theory of transcultural fandom. Participations: Journal of Audience \& Reception Studies, 10(1), 92-108.

Coscarelli, J. (2020, June 22). Why Obsessive K-Pop Fans Are Turning Towards Political Activism. The New York Times. https://www.nytimes.com/2020/06/22/arts/music/k-pop-fans-trump-politics.html

Deen, C. (2014). Formation, Purpose and Gains: An Exploratory Study of Hallyu Fanclubs in the Philippines. Ateneo Korean Studies Conference Proceedings, 1(0), 25-33.

Evangelista, R. (2019). Beyond The (K-pop) Scene: Analyzing the Role of BTS's Love Myself Campaign and Celebrity Diplomacy in the Promotion of UNICEF's Child Protection Campaign. Academia, 1-27.

Fiske, J. (1992). The Cultural Economy of Fandom. In The Adoring Audience: Fan Culture and Popular Media, edited by Lisa A. Lewis, 256. New York: Routledge.

Gogoi, A. (2020, July 18). Who are The BTS Fans Who Raised Rs 5.9 Lakh In a Day for Assam Flood Relief? The Better India. https://www.thebetterindia.com/233176/bts-fans-inspiration-assam-floods-donation-south-korea-bangtan-boys-kpop-ang136/

Han, B. (2017). K-Pop in Latin America: Transcultural Fandom and Digital Mediation. International Journal of Communication, 11, 2250-2269. Retrieved from https://ijoc.org/index.php/ijoc/article/view/6304/2048 
Herman, T. (2017, December 21). K-pop Fans Spend Big On Times Square Ads Promoting Their Favorite Stars. Forbes. https:/www.forbes.com/sites/tamarherman/2017/12/21/k-pop-fans-spend-big-on-times-square-ads-promoting-theirfavorite-stars/\#62f3a4df7105

Horeck, T. (2014). \#AskThicke: "Blurred lines," Rape Culture, and the Feminist Hashtag Takeover. Feminist Media Studies, 14(6), 1105-1107. https://doi.org/10.1080/14680777.2014.975450

Horton, D. \& Wohl, R. R. (1956). Mass communication and para-social interaction: Observations on intimacy at a distance. Psychiatry, 19(3), 215-229. https://doi.org/10.1080/00332747.1956.11023049

Housley, W., Webb, H., Williams, M., Procter, R., Edwards, A., Jirotka, M., Burnap, P., Stahl, B. C., Rana, O., \& Williams, M. (2018). Interaction and Transformation on Social Media: The Case of Twitter Campaigns. Social Media + Society. https://doi.org/10.1177/2056305117750721

Jang, W. \& Song, J. E. (2017). The Influences of K-pop Fandom on Increasing Cultural Contact: With the Case of Philippine Kpop Convention, Inc. Korean Regional Sociology, 18, 29-56.

Jenkins, H. (1992). Textual Poachers: Television Fans and Participatory Culture. London: Routledge.

Jeong, A. (2017, November 28). K-Pop: Stream Like You Breathe. Korea Exposé. https://www.koreaexpose.com/k-popstream-breathe/

Jeong, L. (2020, August 11). K-pop idols BTS, Exo, Shinee and IU get crazy birthday gifts from fans - ads in New York's Times Square, Chanel and Hermes bags - what do fans get in return? The South China Morning Post. https://www.scmp.com/magazines/style/celebrity/article/3096893/k-pop-idols-bts-exo-shinee-and-iu-get-crazy-birthday

King, B. (2008). A Social Movement Perspective of Stakeholder Collective Action and Influence. Business \& Society, 47(1), 21-49. https://doi.org/10.1177/0007650307306636

King, B. G. \& Soule, S. A. (2007). Social Movements as Extra-Institutional Entrepreneurs: The Effect of Protests on Stock Price Returns. Administrative Science Quarterly, 52, 413-442. https://doi.org/10.2189\%2Fasqu.52.3.413

Kuo, L., Perez-Garcia, S., Burke, L., Yamasaki, V., \& Le, T. (2020). Performance, Fantasy, or Narrative: LGBTQ+ Asian American Identity through Kpop Media and Fandom. Journal of Homosexuality. https://doi.org/10.1080/00918369.2020.1815428

Lufadeju, Y. (2018, September 24). We have learned to love ourselves, so now I urge you to 'speak yourself.' Remarks by BTS' Kim Nam Jun (RM) at the launch of Generation Unlimited, at the UN General Assembly. UNICEF. https://www.unicef.org/press-releases/we-have-learned-love-ourselves-so-now-i-urge-you-speakyourself\#: :text=I\%20want\%20to\%20hear\%20your,Nam\%20Jun\%2C\%20RM\%20of\%20BTS

Mahr, K. (2012, March 7). South Korea’s Greatest Export: How K-Pop's Rocking the World. Time. https:/world.time.com/2012/03/07/south-koreas-greatest-export-how-k-pops-rocking-the-world/ 
Marinescu, V., \& Balica, E. (2013). Korean Cultural Products in Eastern Europe: A Case Study of the K-Pop Impact in Romania. Region, 2(1), 113-135. Retrieved from www.jstor.org/stable/43737650

McCurry, J. (2020, June 24). How US K-pop fans became a political force to be reckoned with. The Guardian. https:/www.theguardian.com/music/2020/jun/24/how-us-k-pop-fans-became-a-political-force-to-be-reckoned-with-blmdonald-trump

Pacis, J. J. C. (2012). Popping the K-pop Bubble: A Study on the World of K-pop Fandom as a Subculture. Unpublished Undergraduate Thesis - University of the Philippines College of Mass Communication, University of the Philippines Diliman. Retrieved from https://iskwiki.upd.edu.ph/images/4/4a/PoppingTheK-popBubble.pdf

Pack, S. (2014). K-Popped: South Korean Media Exports in the Philippines. Slovak Ethnology, 4, 522-533. Retrieved from http://works.bepress.com/sam pack/29/

Reddy, S. (2020, June 11). K-pop fans emerge as a powerful force in US protests. BBC News. https://www.bbc.com/news/world-asia-52996705

Roberts, P. F. (2020, June 24). Are K-pop Fans The New Anonymous? Don't Count On It. Forbes. https:/www.forbes.com/sites/paulfroberts/2020/06/24/are-k-pop-fans-the-new-anonymous-dont-count-on$\underline{\mathrm{it} / ? \mathrm{sh}=1849 \mathrm{f} 5 \mathrm{~d} 42 \mathrm{f} 2 \mathrm{~b}}$

Rojas, M. (2020, July 9). ARMY and its incredible global presence, what does a fandom-lit world look like from a researcher's perspective? Korean Culture and Information Service: Talk Talk KOREA. https://www.korea.net/TalkTalkKorea/English/community/community/CMN0000003579

Romano, A. (2018, February 26). How K-pop became a global phenomenon. Vox Media. https://www.vox.com/culture/2018/2/16/16915672/what-is-kpop-history-explained

Romano, A. (2020, June 20). How K-pop fans are weaponizing the internet for Black Lives Matter. Vox Media. https://www.vox.com/2020/6/8/21279262/k-pop-fans-black-lives-matter-fancams-youtubers-protest-support

Singhal, A., \& Svenkerud, P. J. (1994). Pro-socially shareable entertainment television programs: A programming alternative in developing countries. Journal of Development Communication, 5(2), 17-30.

Tanakasempipat, P. (2020, November 2). K-pop's social media power spurs Thailand's youth protests. Reuters. https:/www.reuters.com/article/us-thailand-protests-k-pop/k-pops-social-media-power-spurs-thailands-youthprotests-idUSKBN27I23K

Thrift, S. C. (2014). \#YesAllWomen as Feminist meme event. Feminist Media Studies, 14(6), 1090-1092. https://doi.org/10.1080/14680777.2014.975421

Toussaint, K. (2020, June 5). YouTubers are creating monetized videos about racial justice so you can donate to BLM by streaming. Fast Company. https://www.fastcompany.com/90513380/youtubers-are-creating-monetized-videos-aboutracial-justice-so-you-can-donate-to-blm-by-streaming 
Vargas Meza, X., \& Park, H. W. (2014). Globalization of cultural products: A webometric analysis of kpop in spanishspeaking countries. Quality and Quantity, 49(4), 1345-1360. http://dx.doi.org/10.1007/s11135-014-0047-2

Yang, S. (2019, August 1). Researcher reveals BTS' global success is down to its ARMY. Korea JoongAng Daily. https://koreajoongangdaily.joins.com/2019/08/01/people/Researcher-reveals-BTS-global-success-is-down-to-its$\underline{\text { ARMY/3066245.html }}$

Yim, H. (2020, March 30). Thai K-pop fans trending \#Dispatch to vent frustration at monarchy. The Korea Herald. http://www.koreaherald.com/view.php?ud=20200330000935

Yoon, Kyong. (2017). Global Imagination of K-Pop: Pop Music Fans' Lived Experiences of Cultural Hybridity. Popular Music and Society, 41(4), 373-389. https://doi.org/10.1080/03007766.2017.1292819

Zheng, M. H. Korean Pop Integration into American Music Culture. The Science Survey. https://thesciencesurvey.com/editorial/2018/03/01/korean-pop-integration-into-american-music-culture/ 